\title{
Isolating the human cochlea to generate bone powder for ancient DNA analysis
}

\author{
Ron Pinhasi $\oplus^{1 \star}$, Daniel M. Fernandes ${ }^{1,2}$, Kendra Sirak ${ }^{1,3}$ and Olivia Cheronet $\oplus^{1}$
}

The cortical bone that forms the structure of the cochlea, part of the osseous labyrinth of the inner ear, is now one of the most frequently used skeletal elements in analyses of human ancient DNA. However, there is currently no published, standardized method for its sampling. This protocol describes the preparation of bone powder from the cochlea of fragmented skulls in which the petrous pyramid of the temporal bone is accessible. Using a systematic process of bone removal based on distinct anatomical landmarks and the identification of relevant morphological features, a petrous pyramid is cleaned with a sandblaster, and the cochlea is located, isolated, and reduced to a homogeneous bone powder. All steps are carried out in dedicated ancient DNA facilities, thus reducing the introduction of contamination. This protocol requires an understanding of ancient DNA clean-room procedures and basic knowledge of petrous pyramid anatomy. In 50-65 min, it results in bone powder with endogenous DNA yields that can exceed those from teeth and other bones by up to two orders of magnitude. Compared with drilling methods, this method facilitates a more precise targeting of the cochlea, allows the user to visually inspect the cochlea and remove any residual sediment before the generation of bone powder, and confines the damage to the inner ear region and surface of the petrous portion of fragmentary crania.

Introduction

Rationale and development of the protocol

Over the past 10 years, the 'ancient DNA revolution' has transformed scientists' understanding of the human past. While the first ancient genome was published only in 2010 (ref. ${ }^{1}$ ), >1,000 ancient genomes and partial genomes have been published within the past year alone, providing an unprecedented amount of genomic data from a range of extant and archaic Homo populations ${ }^{2,3}$. As technological and methodological advancements continue to drive the analysis of skeletal material from increasingly ancient time periods and varied geographical contexts, the extent to which longterm preservation of DNA varies both between and within skeletal elements is becoming increasingly clear. Recognizing that successful paleogenomic research begins with the accrual of DNA-rich bone powder, we developed a standardized and replicable sandblasting technique for obtaining such bone powder from the cochlear part of the petrous pyramid $^{4-8}$.

Progress has been made in understanding and computationally accounting for DNA degradation ${ }^{9-11}$; however, there are currently no reliable ways to determine whether samples excavated from a particular archeological context will yield endogenous DNA, except for full genetic analysis ${ }^{12}$. Consequently, protocols have been developed to account for the expectation of low amounts of damaged DNA in archeological samples. For example, the extraction protocol by Dabney et al. ${ }^{13}$ is optimized to equivalently recover DNA fragments of varying lengths, and thus results in a substantial increase of the fraction of ultrashort $(<40 \mathrm{bp})$ DNA molecules recovered, while the single-stranded library preparation protocol by Gansauge and Meyer ${ }^{14}$ is designed for building sequencing libraries from extracts that contain damaged DNA molecules. The latter protocol avoids the loss of molecules with single-strand breaks on both strands, which are entirely lost in double-stranded library preparation. Furthermore, the use of additional contamination-reducing steps at various stages of the DNA-preparation process has become a common way to increase endogenous DNA yields ${ }^{15-19}$. While these optimized protocols improve the recovery of endogenous ancient DNA present in the skeletal material, an equally essential step before their implementation is the use of the most DNA-rich skeletal element as the starting material for analysis.

${ }^{1}$ Department of Evolutionary Anthropology, University of Vienna, Vienna, Austria. ${ }^{2} \mathrm{CIAS}$, Department of Life Sciences, University of Coimbra, Coimbra, Portugal. ${ }^{3}$ Department of Genetics, Harvard Medical School, Boston, MA, USA. *e-mail: ron.pinhasi@univie.ac.at 
Traditionally, ancient DNA studies relied on teeth (with little consideration for any internal variation) or various dense bones (with a particular focus on cortical sections of long bones, metatarsals, and metacarpals) for analysis, owing to the assumption that denser bone tissues consist of more osteocytes per gram of bone-based on their relative density compared with that of spongy, trabecular bone-and therefore better preserve endogenous DNA ${ }^{20-22}$. However, recent research has demonstrated the benefits of specifically targeting the petrous pyramid ${ }^{23-25}$, the part of the temporal bone located at the base of the skull between the sphenoid and occipital bones[26], for ancient DNA analysis.

The effectiveness of using the petrous pyramid for ancient DNA analysis was first assessed in a study of seven prehistoric archeological specimens from Hungary ${ }^{27}$. The results indicated that the percentage of nonclonal human endogenous ancient DNA fragments sequenced from the petrous pyramid samples exceeded those from teeth by 4 - to 16 -fold, and those from postcranial bones (ribs, metatarsals, and a metacarpal) by up to 183-fold. Unfortunately, the teeth included in that comparison were not sampled specifically from the cementum-enriched surface ${ }^{28}$, recently shown to yield high amounts of DNA, particularly when a predigestion step is applied ${ }^{15}$.

\section{Advantages of using the cochlea for ancient DNA analysis}

In addition to making up part of the skull's base, the petrous pyramid also contains a structure known as the osseous labyrinth, a series of interconnected cavities contained within a layer of compact bone. The cavities of the osseous labyrinth include the vestibule, three semicircular canals, and the cochlea. During life, these cavities are filled with perilymph fluid and house the delicate membranous labyrinth, which contains the receptors for the senses of hearing and balance. While initial investigations identified the petrous pyramid as a DNA-rich skeletal element, further research identified variation among different regions of the petrous pyramid ${ }^{7}$.

Specifically, researchers compared genomic data generated from (i) the trabecular (spongy) bone at the apex of the petrous pyramid; (ii) the cortical (dense) bone adjacent to the semicircular canals, the vestibule, and the cochlea; and (iii) the thin cortical bone encircling the cochlea (often referred to simply as 'the cochlea') in ten petrous pyramids from specimens from archeological contexts spanning the Holocene from temperate, hot and humid, and hot and arid environments ${ }^{7}$. The endogenous DNA fractions recovered from the cortical bone surrounding the cochlear part of the osseous inner ear exceeded those obtained from other cortical bone from the same petrous by up to 65 -fold, and those from the trabecular bone of the same petrous by up to 177 -fold ${ }^{7}$. Though the reasons for the optimal preservation of endogenous DNA in the cochlea compared with that in the other regions of the petrous pyramid remain unclear, we hypothesize that the completion of ossification of the cochlea by the sixth month in utero and the near absence of growth and remodeling of the osseous labyrinth throughout life contribute to the high level of DNA preservation. In particular, it is possible that inhibition of remodeling within the osseous labyrinth results in a prolonged maintenance of woven bone that is yellow in color, has a relatively higher proportion of osteocytes, and is typically found in immature and/or rapidly remodeling bones ${ }^{29,30}$.

A recent study compared ancient DNA preservation in tooth cementum and the cochlea from 34 archeological human skeletons from a range of different ages and preservation environments, including 6 Bronze Age individuals from central Asia, 11 Viking Age individuals from England, 7 cremated Iron Age individuals from Denmark, and 10 Historical-period individuals from Denmark $^{28}$. The results confirmed that the cochlea was an overall better substrate than the cementum layer of teeth, with substantially higher endogenous DNA proportions for the cochlea (average of $40.0 \%$ endogenous DNA) than for the cementum (average of $16.4 \%$ endogenous DNA).

The cochlea has since become a targeted skeletal element in human ancient DNA analyses $5,6,8,23-25,31-33$. While the majority of recent ancient DNA studies use the petrous pyramid to provide the necessary bone powder for DNA extraction, they do not describe the specific process used to isolate and obtain bone fractions for paleogenomic analyses, and thus leave the reader uncertain as to whether the cochlea was in fact the part of the osseous inner ear used.

As ancient DNA studies grow in scale and as samples from more ancient time periods and previously unexplored geographic regions become a greater focus, it is increasingly necessary for researchers to effectively use transparent and standardized sampling techniques that balance the destruction of irreplaceable human skeletal remains with the expected analytical results, which hopefully will provide answers to important questions about human history that are best explored with ancient DNA. Supported by research suggesting that the cochlea is one of the most DNA-rich 
skeletal elements from which to obtain bone material for ancient DNA analysis, we provide a detailed protocol for generating bone powder from the cochlear portion of the petrous pyramid via a sandblasting method.

\section{Experimental design}

Balancing destructive sampling with analytical aims

While human remains are an irreplaceable and nonrenewable resource, the analysis of ancient DNA requires bone powder as a raw starting material for analysis. Thus, there will always be some degree of destruction inflicted on a skeletal element that is sampled for ancient DNA analysis. It is at the discretion of the researcher and any involved stakeholders to balance their analytical goals with the irreparable damage that they cause to a skeletal specimen. This should involve determining whether ancient DNA from a specific sample can contribute to the resolution of particular research questions that require genetic analysis, whether the destruction of some part of a skeletal sample would be justified by the resulting genomic data, and what the best method for sampling would be.

While it is possible to obtain bone powder from any skeletal element, the chances of success are greatly improved when an element known to be DNA-rich is used; so far, the cochlea has been shown to be the element most likely to generate positive results ${ }^{7}$. At present, sampling of the cochlea, or other parts of the petrous pyramid, is carried out by various teams, in varying ways, with littledocumented practices-a trend that must be promptly rectified ${ }^{34}$. We recognize that there are several ways in which a researcher might choose to obtain bone powder from the cochlea for ancient DNA analysis, each with unique positive and negative aspects. Here we present the protocol for a sandblasting method that we have found to be most effective for the generation of bone powder with low contamination and high endogenous DNA content.

This sandblasting protocol reliably generates DNA-rich bone powder directly from the cochlea, maximizing chances for successful ancient DNA analysis by reducing the inclusion of any noncochlear bone material. However, it also compromises the external morphology of the petrous pyramid more than other methods ${ }^{35}$. As a result, it might not be the preferred method for archeological samples where the petrous bone morphology is of extremely high value; in such a case, another method or another skeletal element should be used. For example, an alternative method for accessing the cochlea when a petrous is disarticulated involves the use of a Dremel drill with engraver attachments. With that method, it is possible to collect cochlear bone powder by drilling straight into the internal auditory meatus, causing little to no alteration to the external morphology of the petrous. Alternatively, a hole can be made in whichever part of the petrous pyramid is accessible to access the cochlea as directly as possible, as, for example, illustrated in the cranial base drilling protocol ${ }^{35}$. While such approaches preserve external petrous morphology, they may compromise data quality, as both cochlear and surrounding bone may be sampled indiscriminately. Furthermore, all of these methods destroy the internal morphology of the cochlea, resulting in a loss of phenotypic information necessary for studies of the morphology of the inner ear system ${ }^{36}$.

\section{Anthropological stewardship}

While the choice of whether to use this method is up to the individual researchers and stakeholders involved, we emphasize that the sandblasting protocol presented here provides guidelines for obtaining bone powder from the cochlea for fragmented skulls only. In all cases where this protocol is used, the endocranial part of the petrous pyramid should be accessible. Consequently, skulls where the petrous pyramid is completely detached from the temporal bone (which can represent over 50\% of cases in some collections) are ideal. Nevertheless, in cases where the petrous pyramid is still attached to the temporal bone, it can still be sampled in an ancient-DNA-dedicated clean room via the procedure described in this protocol. All remaining material will be untouched and should be returned to the museum or collection as soon as possible after the sampling process.

In cases where a skull is complete or reconstructed, use of the current protocol should be avoided, as it would require the removal of the petrous pyramid, which would result in major structural damage to the cranial vault and/or base ${ }^{35}$. Instead, a previously published cranial base drilling method should be used to access the cochlear part of the osseous labyrinth from the cranial base in a way that minimizes damage to the surrounding cranial features as much as possible ${ }^{35}$. Nevertheless, this drilling method does not allow visualization of the cochlea during the process and consequently reduces the precision of the procedure, leading to the inclusion of a greater amount of noncochlear bone. 
It is essential that all necessary anatomical and morphological data be obtained before any destructive sampling, as anthropological and anatomical analyses of the osseous labyrinth within the petrous pyramid have yielded biologically meaningful information about the growth patterns of the osseous labyrinth ${ }^{37,38}$, sexual dimorphism ${ }^{39}$, locomotion differences and the development of human bipedalism $^{40,41}$, and phylogenetic relationships ${ }^{36,41-43}$. We therefore suggest that researchers restrict the application of this protocol to skeletons with both left and right well-preserved petrous pyramids, and sample only one side whenever possible. In addition, we strongly recommend high-resolution computerized tomography scanning of the petrous pyramid ${ }^{36,44}$ before sampling for ancient DNA analysis, and encourage the deposition of the data in a public repository. Finally, we encourage the sharing of extra bone powder and derived molecular products, including DNA extracts and sequencing libraries, with other laboratories for replication purposes. The combination of these practices will contirbute toward preserving the valuable resource that is the petrous pyramid for future studies.

\section{Downstream sample processing}

The cochlear powder generated with this protocol can be processed via standard methods for ancient DNA. After the generation of bone powder, DNA extraction and the construction of sequencing libraries can be performed. We suggest following the extraction protocol in ref. ${ }^{45}$, which is an updated and optimized version of a widely used silica-based ancient-DNA extraction protocol ${ }^{13}$ that provides column- and bead-based alternatives. Next, double- or single-stranded libraries can be prepared, depending on sample preservation, objectives, and/or cost constraints. While singlestranded library preparation protocols allow the recovery of greater amounts of endogenous DNA ${ }^{14}$, double-stranded protocols are more cost- and time-effective, and thus potentially allow the processing of more samples ${ }^{46}$.

\section{Materials}

\section{Reagents}

- A disarticulated petrous pyramid !CAUTION Ensure that permission to use destructive methods for the purpose of ancient DNA analysis has been obtained from all relevant authorities and/or stakeholders before beginning this protocol.

- 2\% (vol/vol) sodium hypochlorite solution (hereinafter referred to as 'bleach'; Fisher Scientific, cat. no. 11919012) ! CAUTION Sodium hypochlorite solution is alkaline and may cause skin and eye irritation; wear protective clothes and gloves.

- Absolute ethanol (Fisher Scientific, cat. no. 10332562) ! CAUTION Absolute ethanol is flammable and may cause eye irritation; keep away from heat sources and/or sparks.

- DNA-ExitusPlus IF (AppliChem, cat. no. A7089.0500)

- Aluminum oxide sand abrasive $(50 \mu \mathrm{m}$; Skillbond, cat. no. SRE030)

\section{Equipment}

- Polyethylene clear plastic bags (Fisher Scientific, cat. no. 11388193)

- Microcentrifuge tubes (2 ml; Eppendorf, cat. no. 0030 108.116)

- Disposable weighing boats (VWR, cat. no. 611-0094)

- Shortwave UV cross-linker (Analytik Jena, cat. no. 849-30101)

- PCR workstation with integrated shortwave UV lights (VWR, cat. no. 732-2541)

- Sandblasting unit with two tanks and two handpieces (Renfert Basic Master, cat. no. 29482025; see 'Equipment setup' for alternative air-cleaning strategy for single handpiece units)

- Air extraction unit (Renfert, cat. no. 29210050)

- Air compression unit (Implotex, cat. no. NEW-325)

- Mixer mill (Retsch, cat. no. 20.745.0001) $\triangle$ CRITICAL A sufficient number of grinding jars and balls are needed to prepare more than one sample per day. We recommend stainless steel jars (Retsch, cat. no. 01.462.0213) and 12-mm balls (Retsch, cat. no. 05.368.0037). Grinding jars and balls must be thoroughly cleaned between uses ('Equipment setup').

- Disposable overalls (VWR, cat. no. 113-7882)

- Disposable shoe covers (VWR, cat. no. 113-8159)

- Disposable face mask (VWR, cat. no. 113-6221)

- Disposable hair net (VWR, cat. no. 113-8247)

- Disposable nitrile gloves (VWR, cat. no. 112-4195E) 


\section{Equipment setup}

\section{Laboratory requirements}

A clean room dedicated to the processing of ancient samples is required. This clean room should be a specialized, sterile environment that is spatially isolated from any post-PCR facilities containing amplified DNA; many research groups prefer to set up the ancient DNA facility in a separate building from that housing post-PCR laboratories ${ }^{4-50}$. In addition, no ancient DNA facility should have ever been used as a post-PCR laboratory in the past ${ }^{50}$. Researchers should enter the clean room only after dressing in disposable overalls, shoe covers, a facemask, a hair net, and gloves, and should never enter an ancient DNA work facility after having been in a post-PCR laboratory unless they have showered and undergone a complete change of clothes to remove any potential contaminant $\mathrm{DNA}^{43,46}$. In the clean room, chemical cleaning (i.e., wiping with bleach or DNA-degrading detergent such as DNAExitusPlus) must be implemented for all laboratory surfaces and equipment, as well as for anything brought into the $l a b^{48,51,52}$.

\section{Setup of the sandblasting unit}

The sandblasting unit and associated air compression and extraction units should be thoroughly cleaned chemically by thorough wiping with bleach before introduction to the clean room. When the sandblasting unit is brought into the clean room, it should immediately be placed inside the PCR workstation to allow its exposure to UV irradiation for anti-contamination purposes when researchers are not present. We recommend the Renfert Basic Master sandblaster, which has two tanks, one of which can be used for aluminium oxide sand and the other for air, as well as two handpieces for the process of sandblasting.

\section{Considerations about handling and reusable equipment}

The bone samples that will be processed for ancient DNA analysis contain low amounts of damaged DNA. To avoid cross-contamination, only one sample should be processed at a time, and the production of bone powder from a sample should be completed before processing of the next sample begins.

All multiple-use equipment, including the sandblasting chamber and its inner components, the PCR workstation, and the grinding equipment (including the mixer mill and the grinding jars and balls), must be thoroughly sterilized before each use and between uses to prevent cross-contamination. While there are various methods for decontamination of equipment and working surfaces, decontamination should begin with chemical cleaning. Care must be taken with equipment that may be damaged by the use of sodium hypochlorite, such as metal equipment that can become corroded. Thorough chemical cleaning of all surfaces and equipment should take place between samples.

Particular care must be taken with the sterilization of the sandblasting chamber. The chamber grid should be removed and cleaned with bleach and a small wire brush to remove any residual sand or bone material from the open spaces in the grid. It should then be air-dried and chemically cleaned by thorough wiping with bleach before being placed back in the sandblaster. In addition, the area surrounding the sandblaster should be chemically cleaned thoroughly between samples. Grinding jars and balls should be extensively decontaminated by immersion in bleach solution for a minimum of $20 \mathrm{~min}$ and then cleaned with DNA-ExitusPlus or similar, after which any metal components should be wiped with ethanol to remove all traces of bleach to prevent corrosion and, finally, all components should be exposed to UV radiation for at least $30 \mathrm{~min}$ before being stored in clean, individual plastic bags.

When no work is in progress, equipment and working surfaces should be UV-irradiated. If no additional samples are to be worked on during a particular bone-processing session, the sandblaster grid should be removed from the sandblasting chamber so that the chamber can be properly decontaminated by UV irradiation. The sandblasting unit and the surrounding area should be decontaminated by UV irradiation for at least $30 \mathrm{~min}$. This allows deep decontamination of all the equipment, and at a minimum should be done between every ten samples, or on a daily basis if fewer samples are handled.

\section{Procedure}

\section{Sample decontamination and cleanup Timing $15 \mathrm{~min}$}

1 Select isolated petrous pyramids from osteological assemblages while wearing clean nitrile or latex gloves, and place them in sealed plastic bags for storage before processing. Before entering the clean room, wipe the plastic bag containing the petrous pyramid with bleach. Inside the clean room, wipe 

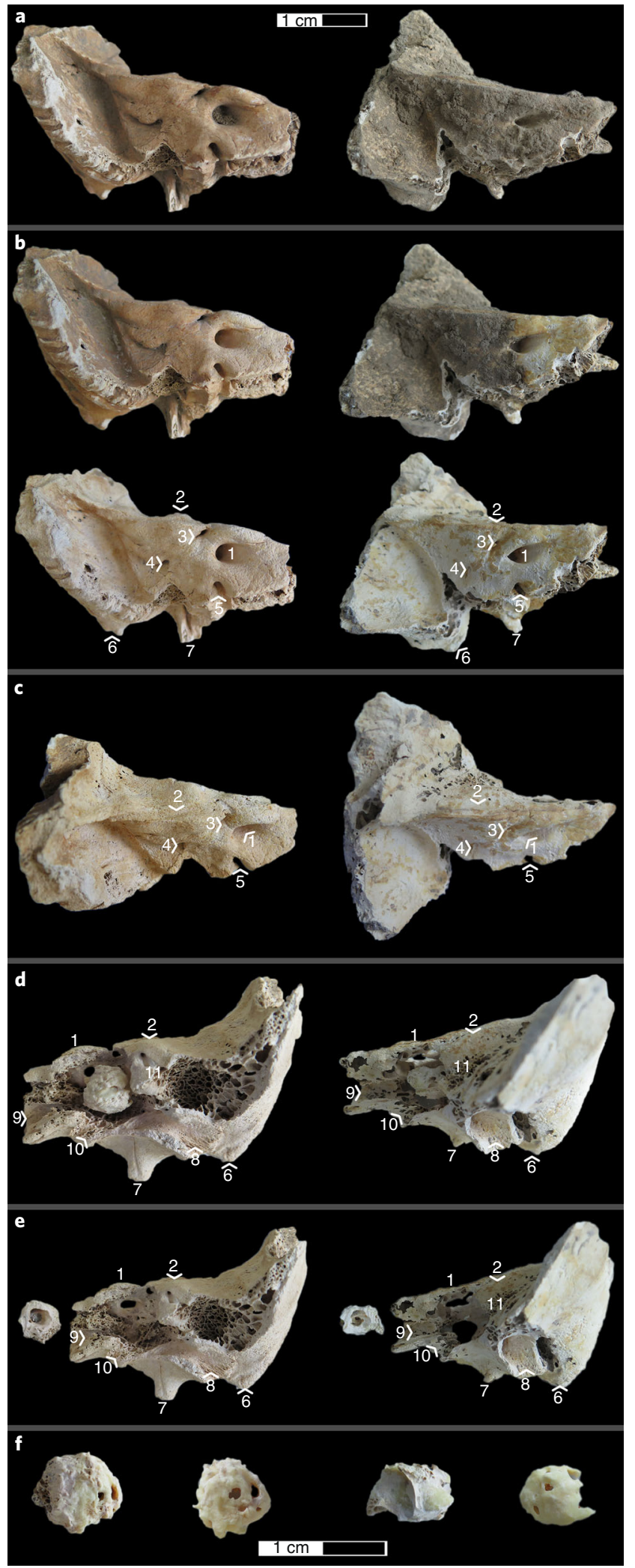

it with bleach again, place it in a shortwave UV cross-linker, and irradiate it for a minimum of 5 min on each side; then remove the bone from the bag and place it into the chamber of the sandblaster (Fig. 1a). 
1 Fig. 1 | Step-by-step walkthrough of the isolation and cleaning of the cochlea for a DNA analysis. Each panel shows two left petrous parts of the temporal bone from two different individuals, one with good preservation (left) and another with poorer preservation (right). a, Posterior view of the petrous pyramid when it is placed into the sandblasting chamber. $\mathbf{b}$, Posterior view of the petrous pyramid during cleaning of the superficial area around the inner auditory meatus (top) and after the complete step (bottom). Arrowheads indicate the approximate locations of the landmarks (defined below). c, Superior view of the petrous pyramid for identification of the landmarks. d, Anterior view of the petrous pyramid with detail of the cochlear part of the inner ear; the location and anatomical variation of the cochlear part of the inner ear at the end of the isolation steps are shown (end of Step 5) before separation of the cochlea from the petrous pyramid. e, Detail of the cochlear part of the inner ear after separation, in no particular orientation. $\mathbf{f}$, Detail of the cochlea before (left) and after (right) the removal of the surrounding dense bone, demonstrating the difference in color between the two. The following landmarks are highlighted in $\mathbf{b}-\mathbf{e}: 1$, internal auditory meatus; 2 , arcuate eminence; 3 , subarcuate fossa; 4, vestibular aqueduct; 5 , cochlear canaliculus; 6, mastoid process; 7, styloid process; 8, tympanic part/external acoustic meatus; 9, carotid canal; 10, jugular fossa (approximate location); 11, semicircular canals. The scale bar in $\mathbf{a}$ applies to $\mathbf{a}-\mathbf{e}$, and the bar in $\mathbf{f}$ applies to only that panel.

2 Using the sandblaster, clean the superficial surface of the petrous pyramid. This includes the removal of superficial dirt, any material that may have been put on the bone for conservation purposes, and any surface that has been in direct human contact.

$\triangle$ CRITICAL STEP Adjust the sandblaster's air pressure according to the preservation of each sample and the experience of the handler, as a lower pressure will allow more delicate work and is especially appropriate for friable or soft bone (the determination of friable or soft bone will be based on the judgment of the researcher). Hold the pen farther from the sample $(>5 \mathrm{~cm})$ to avoid making distinct holes in the bone at this stage (Fig. 1b).

\section{Cochlea isolation Timing Variable; 5-20 min per sample}

3 To identify the location of the cochlea within the petrous pyramid, locate the internal auditory meatus and the semicircular canals on the petrous pyramid, the latter of which are located underneath the arcuate eminence on the anterior surface of the petrous pyramid (Fig. 1c,d). The cochlea will be located slightly anterolateral to the internal auditory meatus and medial to the arcuate eminence and semicircular canals.

\section{? TROUBLESHOOTING}

4 Using the sandblaster and holding the pen close to the sample $(<1 \mathrm{~cm})$ for greater precision, begin to remove surface bone in the area of the cochlea on the anterior surface of the petrous pyramid. This approach exposes the dense bone surrounding the cochlea.

\section{? TROUBLESHOOTING}

5 Continue removing bone until the rounded shape of the superior part of the cochlea can be distinguished. It is possible to identify this superior part of the cochlea from the presence of spongy bone posterior to the cochlea, and the presence of a constriction anterior to the cochlea at the junction with the semicircular canals (the vestibule).

\section{? TROUBLESHOOTING}

6 Extract the cochlea and the surrounding dense bone from the petrous pyramid by making incisions all around it with the sandblaster, going as deep as possible (Fig. 1d). Start with a cut downward on the anterior surface of the petrous pyramid, $\sim 1 \mathrm{~mm}$ from the superior ridge of the pyramid and parallel to the internal auditory meatus. Make another incision through the dense bone area between the cochlea and the semicircular canals. Remove the bone around the carotid canal and the jugular fossa. If possible, depending on the morphology and necessary preservation of your sample, use the jugular fossa to make incisions parallel to the proximal part of the petrous pyramid, on the inferior part of the pyramid.

\section{? TROUBLESHOOTING}

7 Once the cochlea and surrounding dense bone have been separated from the rest of the petrous pyramid (Fig. 1e), remove the surrounding dense bone from the cochlear bone with the sandblaster. $\triangle$ CRITICAL STEP You might need to reduce the sandblasting pressure during this step to avoid unwanted destruction of cochlear bone. The two types of bone can most often be distinguished by a change in color. The precise colors will depend on the preservation of the bone, but the cochlea will often be noticeably darker (Fig. 1f). Furthermore, in poorly preserved, fragile specimens, the two types of bone will form two clearly distinct layers.

$\triangle$ CRITICAL STEP For the best results, it is recommended to remove as much surrounding dense bone as possible; however, a compromise in the ratio of cochlear to surrounding dense bone in the 
final piece must be achieved on a sample-by-sample basis, depending on the required amount of bone powder.

$\Delta$ CRITICAL STEP A typical cochlea yields $100-300 \mathrm{mg}$ of powder, allowing at least one DNA extraction and the storage of surplus bone powder (storage details are described in Step 8). In poorly preserved specimens, the total weight of the cochlear bone alone might not be enough for the user's needs. If the isolated cochlea is not sufficient, some of the semicircular canals can supplement the additional bone powder, and can be further isolated by sandblasting in the area of the arcuate eminence.

\section{? TROUBLESHOOTING}

\section{Cochlea cleanup Timing 2 min}

8 Visually inspect the cochlear bone for any residual dirt or sediment. If present, remove these contaminants from the inside of the cochlea by sandblasting the cochlea in short and controlled bursts to loosen and remove the sediment without unwanted destruction of cochlear bone. Adapt the pressure used depending on the necessary preservation of the sample. Use air from the sandblaster to subsequently clean any residual sand off the bone (Fig. 1f).

- PAUSE POINT At this point, the cochlea can be put in a clean plastic bag and stored in a refrigerated environment indefinitely for later powdering.

\section{Decontamination and powdering Timing 25 min}

9 Place the cochlea in a clean, disposable weigh boat placed in the cross-linker.

10 Place the grinding equipment in the cross-linker, which should be turned on for $10 \mathrm{~min}$.

11 Flip the cochlea after $10 \mathrm{~min}$, and then expose to UV for another $10 \mathrm{~min}$.

12 Remove the cochlea and grinding equipment from the cross-linker.

13 If grinding with a mixer mill, place the cochlea in a grinding jar with a grinding ball and grind at a maximum frequency for two 30-s sessions with a 10-s pause between to allow for the dissipation of any heat built up during the grinding process. Alternatively, a mortar and pestle can be used to grind the sample.

$\triangle$ CRITICAL Some harder, very well-preserved samples may require additional milling. With the mixer mill, this is achieved by additional 30-s grinding cycles separated by pauses of at least $10 \mathrm{~s}$, continued until a homogeneous powder is obtained.

14 Transfer the powder to a clean microcentrifuge tube and store at $4{ }^{\circ} \mathrm{C}$. You might need a spatula to scrape off powder adhering to the inside of the jar.

DAUSE POINT While no controlled experiments regarding sample storage have been performed, it is widely believed that a sample can be stored for a few years under these conditions. If longerterm storage is needed, a temperature of $-20{ }^{\circ} \mathrm{C}$ is preferable.

\section{Downstream processing Timing $48 \mathrm{~h}$}

15 Process the powder according to standard DNA-extraction (e.g., ref. ${ }^{45}$ ) and library-preparation (e.g., ref. ${ }^{46}$ ) procedures. After sequencing, an automated processing pipeline such as EAGER $^{53}$ can be used to map, authenticate, and assess the quality of the raw data.

\section{Troubleshooting}

Troubleshooting advice can be found in Table 1.

Table 1 | Troubleshooting table

\begin{tabular}{llll} 
Step & Problem & Possible reason & Solution \\
\hline 3-5 $\begin{array}{l}\text { Described anatomical } \\
\text { landmarks cannot be } \\
\text { located }\end{array}$ & $\begin{array}{l}\text { Osteological variation } \\
\text { Very poor sample } \\
\text { preservation }\end{array}$ & $\begin{array}{l}\text { The internal auditory meatus should be easily identifiable. If no other } \\
\text { anatomical landmarks can be identified, consider the cochlea as located slightly } \\
\text { anterolateral to the internal auditory meatus and start gradually removing bone } \\
\text { around that area until the rounded shape of the cochlea becomes identifiable } \\
\text { Occasionally, in very poorly preserved samples, landmarks are missing from the } \\
\text { vample. Nevertheless, if the cochlea is present, it can always be identified by }\end{array}$ \\
$\begin{array}{l}\text { preservation } \\
\text { the internal auditory meatus }\end{array}$
\end{tabular}

Table continued 
Table 1 (continued)

\begin{tabular}{|c|c|c|c|}
\hline Step & Problem & Possible reason & Solution \\
\hline 6 & $\begin{array}{l}\text { Described anatomical } \\
\text { landmarks cannot be } \\
\text { located }\end{array}$ & Osteological variation & $\begin{array}{l}\text { At this stage, a general overview of the rounded shape of the cochlea should be } \\
\text { visible. The described landmarks should help you achieve a cleaner cochlear } \\
\text { extraction }\end{array}$ \\
\hline 7 & $\begin{array}{l}\text { No color or texture } \\
\text { differentiation is visible }\end{array}$ & Osteological variation & $\begin{array}{l}\text { As the sandblasting is done from the outside in, a minimum width of the } \\
\text { cochlear walls must be defined so that the user can decide when to stop the } \\
\text { sandblasting. Making a small circular incision through the final cochlear piece } \\
\text { can help you determine how thick the walls are. For situations where there are } \\
\text { no color or texture markers, } \sim 0.5 \mathrm{~mm} \text { of cochlear thickness is a sensible depth } \\
\text { at which to stop }\end{array}$ \\
\hline $3-7$ & $\begin{array}{l}\text { Bone crumbles when it comes in } \\
\text { contact with sandblaster sand }\end{array}$ & Poor preservation & Reduce the air pressure of the sandblaster and handle each piece gently \\
\hline
\end{tabular}

Table 2 | Sequencing and data alignment results

\begin{tabular}{|c|c|c|c|c|c|c|c|c|}
\hline Site & Burial number & Age (BP) & Region of petrous & Total reads & $\begin{array}{l}\text { Aligned } \\
\text { human reads } \\
\text { (hg19) }\end{array}$ & $\begin{array}{l}\text { Deamination } \\
\text { frequency } \\
\left(5^{\prime} \mid 3^{\prime}\right)\end{array}$ & $\begin{array}{l}\text { Endogenous } \\
\text { DNA (\%) }\end{array}$ & $\begin{array}{l}\text { Fold change in } \\
\text { endogenous } \\
\text { DNA }\end{array}$ \\
\hline \multirow[t]{2}{*}{ Vat Komnou } & \multirow[t]{2}{*}{40} & \multirow[t]{2}{*}{$2,150-1,750$} & Cochlea & 448,753 & 1,210 & $0.29 \mid 0.23$ & 0.27 & \\
\hline & & & $\begin{array}{l}\text { Cochlea }+ \text { surrounding } \\
\text { dense bone }\end{array}$ & $1,033,795$ & 1,629 & $0.15 \mid 0.12$ & 0.16 & 1.69 \\
\hline \multirow[t]{2}{*}{ Ain Ghazal } & \multirow{2}{*}{$\begin{array}{l}\text { AG93-CF 3883, } \\
\text { burial } 37\end{array}$} & \multirow[t]{2}{*}{10,000} & Cochlea & 499,025 & 4,864 & $0.29 \mid 0.22$ & 0.97 & \\
\hline & & & $\begin{array}{l}\text { Cochlea }+ \text { surrounding } \\
\text { dense bone }\end{array}$ & $1,062,751$ & 5,472 & $0.15 \mid 0.11$ & 0.51 & 1.90 \\
\hline \multirow[t]{2}{*}{ Barcin } & \multirow[t]{2}{*}{ L10E-106 } & \multirow[t]{2}{*}{8,400} & Cochlea & 524,574 & 237,569 & $0.25 \mid 0.22$ & 45.24 & \\
\hline & & & $\begin{array}{l}\text { Cochlea }+ \text { surrounding } \\
\text { dense bone }\end{array}$ & 856,318 & 257,365 & $0.24 \mid 0.18$ & 30.02 & 1.51 \\
\hline \multirow{2}{*}{$\begin{array}{l}\text { Polgar Ferenci } \\
\text { hat }\end{array}$} & \multirow[t]{2}{*}{ PF280-443 } & \multirow[t]{2}{*}{$6,300-6,100$} & Cochlea & 300,890 & 209,662 & $0.19 \mid 0.14$ & 69.63 & \\
\hline & & & $\begin{array}{l}\text { Cochlea }+ \text { surrounding } \\
\text { dense bone }\end{array}$ & 585,727 & 336,900 & $0.19 \mid 0.13$ & 57.47 & 1.21 \\
\hline \multirow{2}{*}{$\begin{array}{l}\text { Polgar Ferenci } \\
\text { hat }\end{array}$} & \multirow[t]{2}{*}{ PF145-253 } & \multirow[t]{2}{*}{$6,300-6,100$} & Cochlea & 274,912 & 136,372 & $0.18 \mid 0.13$ & 49.58 & \\
\hline & & & $\begin{array}{l}\text { Cochlea }+ \text { surrounding } \\
\text { dense bone }\end{array}$ & 591,326 & 157,107 & $0.20 \mid 0.14$ & 26.55 & 1.87 \\
\hline \multirow[t]{2}{*}{ Kulubnarti S } & \multirow[t]{2}{*}{ KulS5 } & \multirow[t]{2}{*}{1,200} & Cochlea & 370,315 & 148 & - & 0.04 & \\
\hline & & & $\begin{array}{l}\text { Cochlea }+ \text { surrounding } \\
\text { dense bone }\end{array}$ & 800,161 & 517 & - & 0.06 & -1.33 \\
\hline \multirow[t]{2}{*}{ Gomolava } & \multirow[t]{2}{*}{$21-10$} & \multirow[t]{2}{*}{6,600} & Cochlea & 601,924 & 340,212 & $0.19 \mid 0.15$ & 56.47 & \\
\hline & & & $\begin{array}{l}\text { Cochlea }+ \text { surrounding } \\
\text { dense bone }\end{array}$ & $1,209,609$ & 641,064 & $0.18 \mid 0.14$ & 52.94 & 1.07 \\
\hline \multirow{2}{*}{$\begin{array}{l}\text { Polgar Ferenci } \\
\text { hat }\end{array}$} & \multirow[t]{2}{*}{ PF811/1144 } & \multirow[t]{2}{*}{$6,300-6,100$} & Cochlea & 590,117 & 208,758 & $0.18 \mid 0.09$ & 35.36 & \\
\hline & & & $\begin{array}{l}\text { Cochlea }+ \text { surrounding } \\
\text { dense bone }\end{array}$ & $1,170,125$ & 211,911 & $0.18 \mid 0.09$ & 18.10 & 1.95 \\
\hline \multirow[t]{2}{*}{ Parkhai II } & \multirow{2}{*}{$\begin{array}{l}\text { Grave } 162 . \\
\text { burial } 61\end{array}$} & \multirow[t]{2}{*}{$5,000-4,500$} & Cochlea & 280,627 & 100 & - & 0.04 & \\
\hline & & & $\begin{array}{l}\text { Cochlea }+ \text { surrounding } \\
\text { dense bone }\end{array}$ & 610,581 & 281 & - & 0.05 & -1.20 \\
\hline \multirow[t]{2}{*}{ Man Bac } & \multirow[t]{2}{*}{ M12 } & \multirow[t]{2}{*}{$3,800-3,500$} & Cochlea & 497,173 & 3,474 & $0.04 \mid 0.03$ & 0.70 & \\
\hline & & & $\begin{array}{l}\text { Cochlea }+ \text { surrounding } \\
\text { dense bone }\end{array}$ & 890,232 & 3,643 & $0.02 \mid 0.02$ & 0.41 & 1.71 \\
\hline
\end{tabular}

The last column indicates the difference between the percentage of endogenous reads obtained from this protocol performed on cochlea and the combined percentage of endogenous reads from the cochlea and the surrounding dense bone DNA (cochlea + surrounding dense bone). These data were originally published and described in ref. ${ }^{7}$.

Steps 1 and 2, sample decontamination and cleanup: $15 \mathrm{~min}$ Steps 3-7, cochlea isolation: variable; 5-20 min per sample

Step 8, cochlea cleanup: 2 min

Steps 9-14, decontamination and powdering: $25 \mathrm{~min}$

Step 15, downstream processing: DNA extraction (22 h), library preparation (5-9 h), and raw data analysis (17 h) 

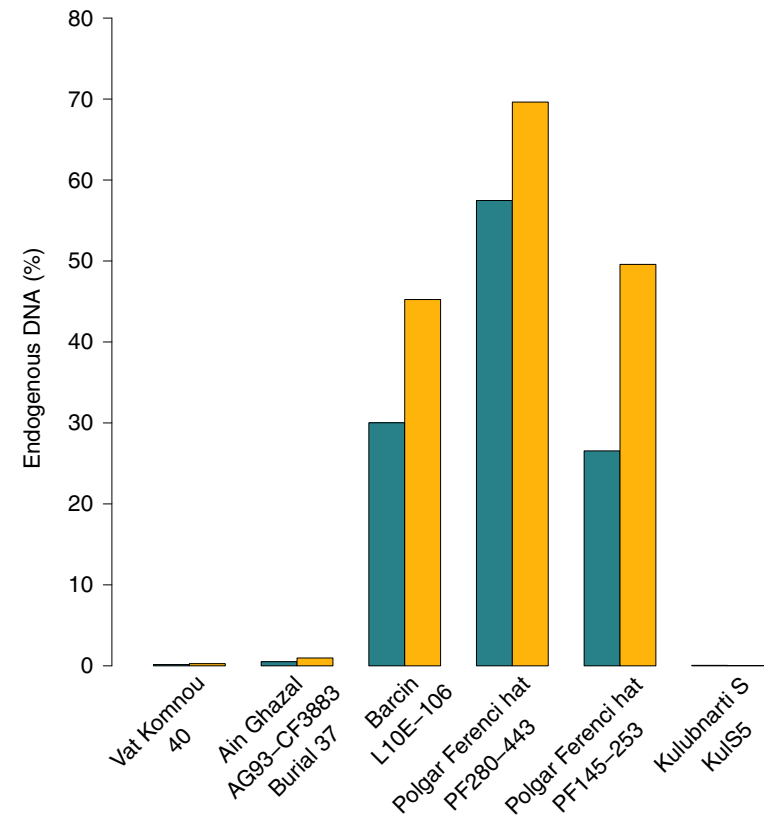

Cochlea and surrounding dense bone Cochlea

Fig. 2 | Comparative yields of endogenous ancient DNA obtained from the cochlea alone and from the cochlea plus the surrounding dense bone. The plotted data are from Table 2. Endogenous DNA was calculated as the percentage of reads aligning to hg19 out of the total number of sequenced reads. Because of the generally lower amounts of endogenous DNA present in the dense bone surrounding the cochlea ${ }^{21}$, its inclusion during ancient DNA processing will dilute the final endogenous amounts.

In general, higher yields of endogenous DNA are expected when the cochlea is used for ancient DNA analysis than when most other skeletal elements or teeth are used. In Table 2, we present reanalyzed lowcoverage shotgun sequencing results from ten individuals dating between 10,000 and $1200 \mathrm{BP}$ (Before Present), using samples obtained with the current protocol for bone powder produced directly from the cochlea. In this experiment, the surrounding dense bone was not discarded and was also powdered for DNA extraction. This allowed us to compare sequencing results from DNA isolated from the cochlear bone powder alone to the results obtained with combined DNA from cochlea and nondiscarded surrounding dense portions of the petrous pyramid ${ }^{7}$. After low-coverage shotgun sequencing of the two regions and data processing as described in ref. ${ }^{7}$, we analyzed the results for the cochlea versus the merged data of the two regions, and determined that the former yielded higher endogenous DNA content in eight out of ten cases, on the basis of the ratio of reads aligning to the human genome versus the total number of reads. In these cases, the endogenous DNA yield from the cochlea was 1.07-fold to 1.95-fold higher than that of the combined cochlea and the surrounding dense bone (Fig. 2, Table 2). Additionally, we investigated the damage signal, used as an indicator of authentic ancient DNA and identified by determining the fraction of reads with deaminated bases at terminal positions ${ }^{9}$. When only the cochlea was used, we identified a higher substitution frequency at the last base pair of each end of the molecule in six out of eight cases where damage was quantifiable, suggesting the presence of authentic ancient DNA. These results suggest that the current protocol is an effective way to consistently produce the most DNA-rich bone powder possible, even when molecular preservation is expected to be poor. Importantly, small increases in the amount of DNA retrieved from a sample will make a substantial difference in the downstream generation of robust amounts of data for population genetic analysis.

\section{Reporting Summary}

Further information on research design is available in the Nature Research Reporting Summary linked to this article.

\section{Data availability}

The raw sequencing data that support the findings of this study have been deposited in the Sequence Read Archive under accession code SRP058345. 
1. Rasmussen, M. et al. Ancient human genome sequence of an extinct Palaeo-Eskimo. Nature 463, 757-762 (2010).

2. Slatkin, M. \& Racimo, F. Ancient DNA and human history. Proc. Natl. Acad. Sci. USA 113, 6380-6387 (2016).

3. Pickrell, J. \& Reich, D. Towards a new history and geography of human genes informed by ancient DNA. Trends Genet. 30, 377-389 (2014).

4. Huerta-Sánchez, E. et al. Altitude adaptation in Tibetans caused by introgression of Denisovan-like DNA. Nature 512, 194-197 (2014).

5. Lazaridis, I. et al. Genomic insights into the origin of farming in the ancient Near East. Nature 536, 419-424 (2016).

6. Mathieson, I. et al. Genome-wide patterns of selection in 230 ancient Eurasians. Nature 528, 499-503 (2015).

7. Pinhasi, R. et al. Optimal ancient DNA yields from the inner ear part of the human petrous bone. PLoS One 10, e0129102 (2015).

8. Skoglund, P. et al. Genomic insights into the peopling of the Southwest Pacific. Nature 538, 510-513 (2016).

9. Jónsson, H., Ginolhac, A., Schubert, M., Johnson, P. L. F. \& Orlando, L. mapDamage2.0: fast approximate Bayesian estimates of ancient DNA damage parameters. Bioinformatics 29, 1682-1684 (2013).

10. Ginolhac, A., Rasmussen, M., Gilbert, M. T. P., Willerslev, E. \& Orlando, L. mapDamage: testing for damage patterns in ancient DNA sequences. Bioinformatics 27, 2153-2155 (2011).

11. Briggs, A. W. et al. Patterns of damage in genomic DNA sequences from a Neandertal. Proc. Natl. Acad. Sci. USA 104, 14616-14621 (2007).

12. Bollongino, R., Tresset, A. \& Vigne, J.-D. Environment and excavation: pre-lab impacts on ancient DNA analyses. Comptes Rendus Palevol 7, 91-98 (2008).

13. Dabney, J. et al. Complete mitochondrial genome sequence of a Middle Pleistocene cave bear reconstructed from ultrashort DNA fragments. Proc. Natl. Acad. Sci. USA 110, 15758-15763 (2013).

14. Gansauge, M.T. et al. Single-stranded DNA library preparation from highly degraded DNA using T4 DNA ligase. Nucleic Acids Res 45, e79 (2017).

15. Damgaard, P. B. et al. Improving Access to Endogenous DNA in Ancient Bones and Teeth (Springer, New York, 2015).

16. Korlević, P. et al. Reducing microbial and human contamination in DNA extractions from ancient bones and teeth. Biotechniques 59, 87-93 (2015).

17. Boessenkool, S. et al. Combining bleach and mild predigestion improves ancient DNA recovery from bones. Mol. Ecol. Resour. 17, 742-751 (2016).

18. Nieves-Colón Maria, A. et al. Comparison of two ancient DNA extraction protocols for skeletal remains from tropical environments. Am. J. Phys. Anthropol. 166, 824-836 (2018).

19. Hajdinjak, M. et al. Reconstructing the genetic history of late Neanderthals. Nature 555, 652-656 (2018).

20. Götherström, A., Collins, M. J., Angerbjörn, A. \& Lidén, K. Bone preservation and DNA amplification. Archaeometry 44, 395-404 (2002).

21. Sosa, C. et al. Association between ancient bone preservation and DNA yield: a multidisciplinary approach. Am. J. Phys. Anthropol. 151, 102-109 (2013).

22. Ottoni, C. et al. Preservation of ancient DNA in thermally damaged archaeological bone. Naturwissenschaften 96, 267-278 (2009).

23. Lipson, M. et al. Ancient genomes document multiple waves of migration in Southeast Asian prehistory. Science 361, 92-95 (2018).

24. Lipson, M. et al. Population turnover in Remote Oceania shortly after initial settlement. Curr. Biol. 28, 1157-1165 (2018).

25. Skoglund, P. et al. Reconstructing prehistoric African population structure. Cell 171, 59-71 (2017).

26. Standring, S. Gray's Anatomy E-Book: The Anatomical Basis of Clinical Practice (Elsevier Health Sciences, Philadelphia, 2015).

27. Gamba, C. et al. Genome flux and stasis in a five millennium transect of European prehistory. Nat. Commun. 5, 1-9 (2014).

28. Hansen, H. B. et al. Comparing ancient DNA preservation in petrous bone and tooth cementum. PLoS One 12, e0170940 (2017).

29. Hernandez, C. J., Majeska, R. J. \& Schaffler, M. B. Osteocyte density in woven bone. Bone 35, 1095-1099 (2004).

30. Rask-Andersen, H. et al. Human cochlea: anatomical characteristics and their relevance for cochlear implantation. Anat. Rec. 295, 1791-1811 (2012).

31. Douka, K. et al. Direct radiocarbon dating and DNA analysis of the Darra-i-Kur (Afghanistan) human temporal bone. J. Hum. Evol. 107, 86-93 (2017).

32. Lazaridis, I. et al. Genetic origins of the Minoans and Mycenaeans. Nature 548, 214-218 (2017).

33. Mathieson, I. et al. The genomic history of southeastern Europe. Nature 555, 197-203 (2018).

34. Prendergast, M. E. \& Sawchuk, E. Boots on the ground in Africa's ancient DNA 'revolution': archaeological perspectives on ethics and best practices. Antiquity 92, 803-815 (2018).

35. Sirak, K. A. et al. A minimally-invasive method for sampling human petrous bones from the cranial base for ancient DNA analysis. Biotechniques 62, 283-289 (2017). 
36. Ponce de León, M. S. et al. Human bony labyrinth is an indicator of population history and dispersal from Africa. Proc. Natl. Acad. Sci. USA 115, 4128-4133 (2018).

37. Jeffery, N. \& Spoor, F. Prenatal growth and development of the modern human labyrinth. J. Anat. 204, 71-92 (2004).

38. Richard, C. et al. New insight into the bony labyrinth: a microcomputed tomography study. Auris Nasus Larynx 37, 155-161 (2010).

39. Benjamin, O. et al. Sexual dimorphism of the bony labyrinth: a new age-independent method. Am. J. Phys. Anthropol. 151, 290-301 (2013).

40. Spoor, F. The semicircular canal system and locomotor behaviour, with special reference to hominin evolution. Courier Forschungsinstitut Senckenberg 243, 93-104 (2003).

41. Spoor, F., Wood, B. \& Zonneveld, F. Implications of early hominid labyrinthine morphology for evolution of human bipedal locomotion. Nature 369, 645-648 (1994).

42. Philipp, G., Marissa, R., Melanie, K., Jean-Jacques, H. \& Fred, S. The mammalian bony labyrinth reconsidered, introducing a comprehensive geometric morphometric approach. J. Anat. 220, 529-543 (2012).

43. Hublin, J. J., Spoor, F., Braun, M., Zonneveld, F. \& Condemi, S. A late Neanderthal associated with Upper Palaeolithic artefacts. Nature 381, 224-226 (1996).

44. Jackler, R. K. \& Dillon, W. P. Computed tomography and magnetic resonance imaging of the inner ear. Otolaryngol. Head Neck Surg. 99, 494-504 (1988).

45. Rohland, N., Glocke, I., Aximu-Petri, A. \& Meyer, M. Extraction of highly degraded DNA from ancient bones, teeth and sediments for high-throughput sequencing. Nat. Protoc. 13, 2447-2461 (2018).

46. Meyer, M. \& Kircher, M. Illumina sequencing library preparation for highly multiplexed target capture and sequencing. Cold Spring Harb. Protoc. 2010, pdb.prot5448 (2010).

47. Cooper, A. \& Poinar, H. N. Ancient DNA: do it right or not at all. Science 289, 1139 (2000).

48. Knapp, M., Clarke, A. C., Horsburgh, K. A. \& Matisoo-Smith, E. A. Setting the stage-building and working in an ancient DNA laboratory. Ann. Anat. 194, 3-6 (2012).

49. Pääbo, S. et al. Genetic analyses of ancient DNA. Ann. Rev. Genet. 38, 645-679 (2004).

50. Poinar, H. N. The top 10 list: criteria of authenticity for DNA from ancient and forensic samples. Int. Cong. Ser. 1239, 575-579 (2003).

51. Fulton, T. L. Setting up an ancient DNA laboratory. in Ancient DNA (eds Shapiro, B. \& Hofreiter, M.) 1-11 (Humana Press, New York, 2012).

52. Champlot, S. et al. An efficient multistrategy DNA decontamination procedure of PCR reagents for hypersensitive PCR applications. PLoS One 5, e13042 (2010).

53. Peltzer, A. et al. EAGER: efficient ancient genome reconstruction. Genome Biol. 17, 60 (2016).

\section{Acknowledgements}

We thank E. Harney, P. Skoglund, and D. Reich for their comments on the manuscript. Support for this project was provided by ERC starting grant ADNABIOARC (263441) to R.P.

\section{Author contributions}

R.P. conceived and developed the concept, and provided supervision. D.F., O.C., and K.S. designed the protocol and contributed expertise. R.P., D.F., O.C., and K.S. contributed equally to the writing and editing of the manuscript.

\section{Competing interests}

The authors declare no competing interests.

\section{Additional information}

Supplementary information is available for this paper at https://doi.org/10.1038/s41596-019-0137-7.

Reprints and permissions information is available at www.nature.com/reprints.

Correspondence and requests for materials should be addressed to R.P.

Publisher's note: Springer Nature remains neutral with regard to jurisdictional claims in published maps and institutional affiliations.

Received: 14 May 2018; Accepted: 10 January 2019;

Published online: 6 March 2019

\section{Related links}

Key references using this protocol

Pinhasi, R. et al. PLoS One 10, e0129102 (2015): https://doi.org/10.1371/journal.pone.0129102

Skoglund, P. et al. Nature 538, 510-513 (2016): https://doi.org/10.1038/nature19844

Lazaridis, J. et al. Nature 536, 419-424 (2016): https://doi.org/10.1038/nature19310

Mathieson, I. et al. Nature 528, 499-503 (2015): https://doi.org/10.1038/nature16152 


\section{Reporting Summary}

Nature Research wishes to improve the reproducibility of the work that we publish. This form provides structure for consistency and transparency in reporting. For further information on Nature Research policies, see Authors \& Referees and the Editorial Policy Checklist.

\section{Statistics}

For all statistical analyses, confirm that the following items are present in the figure legend, table legend, main text, or Methods section.

n/a Confirmed

\ $\square$ The exact sample size $(n)$ for each experimental group/condition, given as a discrete number and unit of measurement

Х $\square$ A statement on whether measurements were taken from distinct samples or whether the same sample was measured repeatedly

$\square$ The statistical test(s) used AND whether they are one- or two-sided

$\triangle \square$ Only common tests should be described solely by name; describe more complex techniques in the Methods section.

Х $\square$ A description of all covariates tested

Х $\square$ A description of any assumptions or corrections, such as tests of normality and adjustment for multiple comparisons

\ $\square$ A full description of the statistical parameters including central tendency (e.g. means) or other basic estimates (e.g. regression coefficient)

$\bigotimes$ AND variation (e.g. standard deviation) or associated estimates of uncertainty (e.g. confidence intervals)

$\searrow \square$ For null hypothesis testing, the test statistic (e.g. $F, t, r$ ) with confidence intervals, effect sizes, degrees of freedom and $P$ value noted

$\triangle \square$ Give P values as exact values whenever suitable.

Х $\square$ For Bayesian analysis, information on the choice of priors and Markov chain Monte Carlo settings

$\square \square$ For hierarchical and complex designs, identification of the appropriate level for tests and full reporting of outcomes

Х $\square$ Estimates of effect sizes (e.g. Cohen's $d$, Pearson's $r$ ), indicating how they were calculated

Our web collection on statistics for biologists contains articles on many of the points above.

\section{Software and code}

Policy information about availability of computer code

Data collection n/a

Data analysis n/a

For manuscripts utilizing custom algorithms or software that are central to the research but not yet described in published literature, software must be made available to editors/reviewers. We strongly encourage code deposition in a community repository (e.g. GitHub). See the Nature Research guidelines for submitting code \& software for further information.

\section{Data}

Policy information about availability of data

All manuscripts must include a data availability statement. This statement should provide the following information, where applicable:

- Accession codes, unique identifiers, or web links for publicly available datasets

- A list of figures that have associated raw data

- A description of any restrictions on data availability

n/a

\section{Field-specific reporting}

Please select the one below that is the best fit for your research. If you are not sure, read the appropriate sections before making your selection. $\bigotimes$ Life sciences $\quad \square$ Behavioural \& social sciences $\square$ Ecological, evolutionary \& environmental sciences For a reference copy of the document with all sections, see nature.com/documents/nr-reporting-summary-flat.pdf 


\section{Life sciences study design}

All studies must disclose on these points even when the disclosure is negative.

Sample size It is a protocol paper and so this is not applicable

Data exclusions It is a protocol paper and so this is not applicable

Replication It is a protocol paper and so this is not applicable

Randomization It is a protocol paper and so this is not applicable

Blinding It is a protocol paper and so this is not applicable

\section{Reporting for specific materials, systems and methods}

We require information from authors about some types of materials, experimental systems and methods used in many studies. Here, indicate whether each material, system or method listed is relevant to your study. If you are not sure if a list item applies to your research, read the appropriate section before selecting a response.

\begin{tabular}{|c|c|}
\hline $\mathrm{n} / \mathrm{a}$ & Involved in the study \\
\hline$\bigotimes$ & Antibodies \\
\hline Х & Eukaryotic cell lines \\
\hline Х & Palaeontology \\
\hline$\bigotimes$ & Animals and other organisms \\
\hline$\bigotimes$ & Human research participants \\
\hline 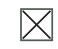 & Clinical data \\
\hline
\end{tabular}

\section{Methods}

$\mathrm{n} / \mathrm{a}$ Involved in the study

\ $\square$ ChIP-seq

Х $\square$ Flow cytometry

$\bigotimes \square$ MRI-based neuroimaging 